\title{
Party Formation and Minority Ideological Positions ${ }^{1}$
}

\author{
Vincent Anesi ${ }^{2}$ \\ University of Nottingham \\ Philippe De Donder \\ Toulouse School of Economics (GREMAQ-CNRS and IDEI)
}

24th July 2008

\footnotetext{
${ }^{1}$ This paper has been presented at the Third CORE Summer School on Heterogeneity and at the WZB (Berlin), the University of Massachusets at Amherst and at the Harvard-MIT Seminar in Positive Political Economy. We thank participants, A. Dixit, J. Roemer, K. Shepsle, J. Snyder and S. Weber for their suggestions. All errors and shortcomings are ours.

${ }^{2}$ Corresponding author. Address: School of Economics, Room B18, The Sir Clive Granger Building, University of Nottingham, University Park, Nottingham NG7 2RD, United Kingdom . Email: vincent.anesi@nottingham.ac.uk.
} 


\begin{abstract}
We develop a model where voters differ in their exogenous income and in their ideological views, with racism as an illustration. Electoral competition, modeled à la Levy (2004), takes place between an endogenous number of parties which propose platforms consisting of both an ideological and an economic dimension. Our objective is to explain the emergence of minority ideological positions (racist policies in our illustration), and to understand the role played by political parties in this emergence. We first show that, in a pure citizen-candidate model where parties are absent, the only equilibrium consists of the majority ideological position. We then show that allowing for the formation of political parties generates equilibria with minority ideological positions. Our main result states that, if the economic issue is sufficiently salient compared to the ideological one, all equilibria consist of a racist policy, and that the lowest degree of racism of these policies increases with the proportion of poor people in the economy. Finally, our result suggests that these minority ideological policies are more likely when the distribution of income is very polarized.
\end{abstract}

JEL Code: D72

Keywords: electoral competition, political parties, racism, polarization, salience. 


\section{Introduction}

In recent years, several European countries have seen the emergence of extreme right parties, who advocate policies with a strong xenophobic or racist component. Paraphrasing a resolution adopted by the Political Affairs Committee of the Council of Europe Parliamentary Assembly on 26 June 2003 (Document 9890):

The tendency today is for extremism to spread across the European continent. In western Europe extremist parties and movements have achieved significant electoral scores. In other member countries of the Council of Europe political extremism has also developed to a noticeable extent. [...] Extremism corresponds to a form of political activity which rejects the principles of parliamentary democracy, basing its ideology and its practices on intolerance, exclusion, xenophobia, anti-Semitism and ultranationalism.

Examples of such countries include France (where in 2002 the extreme right candidate J.M. Le Pen made it into the second round of the Presidential elections), Denmark (where the ruling coalition formed by the Liberal Party and the Conservatives has relied upon the Parliamentary support of the anti-immigrant Danish People's party ${ }^{1}$ ), Austria (with Jorg Haïder's xenophobic Freedom Party, which gathered a spectacular 27\% of votes in the 1999 legislative election) and Belgium (where the Vlaamse Blok/Vlaamse Belang has become the most popular party in Antwerp, the second largest city), to name a few.

At the same time, it is not obvious that people/voters were becoming more racist. Roemer and Van der Straeten (2004a) have looked at the distribution of immigration-related feelings among french voters in 1988, 1995 and 2002 (three Presidential election years) and have discovered "a peak in anti-immigration in 1995" (i.e., before the election where Le Pen made it into the second round) and that "these shifts over time are quite small."

One can also make the point that the majority of people is not racist in Europe, including those countries. Roemer and Van der Straeten (2005) quote a 1997 Eurobaromètre poll where people self declare how racist they feel on a ten point scale. The proportion of people who declare themselves moderately to very racist varies from less than $15 \%$ in Luxembourg to slightly

\footnotetext{
${ }^{1}$ As a consequence, the ruling coalition passed in May 2002 a law restricting the rights of immigrants in many ways (stricter conditions for refugee status, for permanent-resident status, for reunification with spouse or parents, etc.)
} 
less than $50 \%$ in Belgium and France. The average proportion of (moderate to very) racist people in the EU-15 countries is below $40 \%$ and is larger than one half in no EU-15 country.

This then prompts the following question: How can racist policies democratically emerge in societies where a majority of people is not racist? The answer to this question is the central theme of the present paper. In particular, we are especially interested in ascertaining the role (if any) of political party formation in this emergence. More generally, we are interested in shedding light on the role that political party formation plays in allowing minority ideological positions to be selected in democracies. Beyond racism, ideology could also represent positions on abortion, stem cell research, gun control, civil rights, or the importance of protecting individual liberties in the face of terrorism.

To explore these issues, we propose a model in which political parties form endogenously and propose policies that are two-dimensional, with an economic component (redistributive taxation) and an ideological one. The political economy literature has shown that a two-dimensional electoral model represents very well the electoral process in western democracies, and moreover that the economic and ideological dimensions are precisely the two dimensions that play the most important role. Poole and Rosenthal (1991) makes this point for the US, Laver and Hunt (1992) for 20 countries, and Kitschelt (1994) for the main European countries for the past 30 years.

We have chosen to frame this paper in terms of racism, for two reasons. First, because it is easier to be concrete and to write about "racists" rather than "holders of a minority ideological view". Second, because racism is a well documented ideological dimension where a case can be made that minority racist positions are sometimes enacted by democracies (see above). Racism is also an important enough dimension to affect citizens' votes. Roemer and Van der Straeten (2004a) show that, in France, for the three Presidential elections prior to 2007, economic (unemployment, social inequalities) and immigration and law-and-order issues were by far the two most common dimensions that voters say they take into account when deciding how to vote. A similar result holds for Denmark, as shown by Roemer and Van der Straeten (2004b). We would like to stress that, while the model is framed in terms of racism, we believe that our results can be applied more generally to other ideological dimensions. In other words, we view racism as an illustration of more general results pertaining to party formation and ideological minority views.

In our model, society is composed of four homogenous groups of voters, which differ according to their preferences for both the economic policy (how much to redistribute income) and the more or less "racist" policy. We as- 
sume that a majority of voters prefer a large redistributive system. This is driven by the fact that the median income is below the average income in virtually all countries. As for racism, we assume in accordance with the above observations that a majority of people hold non-racist views. We do not make any assumption about the correlation between preferences across the two dimensions, except to assume that there are more non-racist than racist people in all groups, whatever their preferences for redistribution. ${ }^{2}$

Party formation is modeled as in Levy (2004). Each group is represented by a single politician, a citizen-candidate whose only credible political platform when running alone is the most-preferred policy of the group s/he represents. These politicians may also coalesce and form parties. A central assumption of Levy's model is that political parties provide a commitment device to their members ${ }^{3}$ : parties can commit to any policy that belongs to the Pareto set of their members. Thus, the larger the membership of a party, the larger the set of platforms it can credibly announce during the electoral campaign. After the party structure is determined, parties compete in a winner-takes-all election which in turn determines a racism/redistribution policy for the economy.

To highlight the impact of party formation on the racism of equilibrium policies, we first study the benchmark case in which politicians do not form parties. As might have been expected from the distribution of preferences, only non-racist redistributive policies emerge at equilibrium in the absence of parties (Proposition 1). Proposition 2 then shows that, as soon as we allow for party formation, we obtain equilibria where racist policies are proposed and implemented with a strictly positive probability. Therefore, an implication of our model is that party formation is a necessary (but admittedly not a sufficient) condition for the emergence of minority ideological positions. Finally, Proposition 3 states the main result of our paper: When the income distribution is highly polarized, the only policies that emerge at equilibrium are racist policies, and the minimum degree of racism of implemented policies increases with the proportion of poor voters in the electorate. The basic intuition for these results is that income polarization divides the non-racist, thus causing the formation of parties in which racist politicians have a strong bargaining power in the choice of electoral platforms. Also, the bargaining power of the poor racist candidate increases with the proportion of poor people, leading to a larger minimum level of racism at equilibrium.

\footnotetext{
${ }^{2}$ This assumption is stricter than necessary to obtain our results, but we do not mind making it because it biases the model against the adoption of racist policies.

${ }^{3}$ Morelli (2004) also emphasizes the role of political parties as commitment devices.
} 


\section{Related Literature}

The paper closest to ours is Roemer (1998). We borrow its description of the voters' preferences but we adopt a different way to model electoral competition. The common theme between the two papers is that, in a twodimensional electoral competition model, if the saliency of one dimension is large enough, political competition drives parties to compromise on the other dimension. Roemer's objective is to explain why the poor do not expropriate the rich - i.e., why a confiscatory tax rate is not proposed at equilibrium even if it is the most-preferred economic policy of a majority of voters. Observe that we could have phrased our paper in the same way: rather than focusing on ideology we could have focused on the economic dimension and ask the same question as Roemer's. Given the symmetry in the way we model the two dimensions, we would have obtained that only non expropriation policies emerge at equilibrium if ideology is salient enough.

Beyond this common theme, the mechanisms through which political competition affects the equilibrium policies are very different in the two papers. First, Roemer's results depend crucially on the correlation between preferences for taxation and for ideology in the voting population: his nonexpropriation result requires that the median income of the cohort of voters with the median ideological view be larger than the average income in the economy. By contrast, our results do not depend on the correlation between preferences. Also, Roemer focuses on the equilibrium proposal of one party, while our results pertain to any proposal played at equilibrium by any party. Finally, Roemer assumes that parties are exogenous: there are two parties, one representing poor non-racist voters while the other represents rich racist voters (in our parlance). Unlike our paper, he does not focus on the impact of endogenous party formation on the equilibrium.

Another related approach consists of the empirical contributions by Roemer and Van der Straeten (2004a,2004b) and by Lee and Roemer (2005), who develop a political competition model with a two-dimensional (economic and ideological) policy space. In these papers, Roemer and his coauthors study for three countries (France, Denmark and the US) how the anti-immigrant (in the European case) or the racist (for the US) feelings among voters impact the equilibrium position of parties on the economic issue. Their objective is to calibrate a model of political competition (using party unanimity Nash equilibrium as the political equilibrium concept) and to assess numerically the impact of the ideological dimension on the equilibrium economic policy.

Two other papers have recently developed different political-economy models where the presence of a second policy issue affects income redistribution. First, Austen-Smith and Wallerstein (2006) use a model of legislative 
politics to study the consequences of ethnic divisions for redistributive policy choice. They show how the introduction of an additional policy dimension, namely affirmative action, benefits the skilled members of both the majority (white) and minority (black) group, but hurts unskilled whites and blacks. Fernandez and Levy (2008) also examine how diversity in preferences over a second policy dimension affects income redistribution between rich and poor. Although they use a model of collective choice similar to ours, their problematic is quite different. While members of both income classes disagree on a (non-economic) race policy in our model, they assume instead that the poor have opposing views on how tax revenues should be allocated across specialinterest projects (or targeted public goods). They show how increased taste conflict among the poor first dilutes but then reinforces class interests.

Finally, Glaeser (2005) presents a signaling model in which politicians spread hatred (anti-Black hatred, anti-Semitism ...) when their policies are detrimental to an out-group because hatred creates a desire among voters to harm that group. He thus shows that hatred will be spread against poor minorities by anti-redistribution candidates, and spread against rich minorities by pro-redistribution candidates.

\section{The Model}

We first describe the economic environment and then move to the electoral competition aspects.

\subsection{The Economic Model}

Consider the following adaptation of the model introduced by Roemer (1998). The economy is composed of four homogenous groups of voters, none of which forms a majority. These groups are differentiated by their members' pre-tax income, $\omega \in\left\{\omega_{\ell}, \omega_{h}\right\}$ with $\omega_{\ell}<\omega_{h}$, and most-preferred racial view, $\rho \in\left\{\rho^{-}, \rho^{+}\right\}$with $\rho^{-}<\rho^{+}$. We assume, without loss of generality, that the more racist individuals are those whose racial view is $\rho^{+}$. Let $\Theta \equiv$ $\left\{\omega_{\ell}, \omega_{h}\right\} \times\left\{\rho^{-}, \rho^{+}\right\}$be the type space, with generic element $\theta_{i}^{j} \equiv\left(\omega_{i}, \rho^{j}\right)$. The fraction of the population that is of type $\theta_{i}^{j}$ is denoted by $\mu_{i}^{j}$, where $\mu_{i}^{j}<1 / 2$ for every $i \in\{\ell, h\}$ and $j \in\{-,+\}$. The joint distribution of types is fully described in Table 1.

\section{[TABLE 1 HERE]}

We assume that the poor and the non-racist are both majority coalitions: $\mu_{\ell}>1 / 2$ and $\mu^{-}>1 / 2$. The first assumption is justified by the observation 
that the median income is below the average income in all OECD countries. The second assumption comes from our desire to explain how a racist policy may emerge even when a majority of voters does not hold such a position. We further assume that the non-racists constitute a majority within both income groups: $\mu_{\ell}^{-}>\mu_{\ell}^{+}$and $\mu_{h}^{-}>\mu_{h}^{+}$. Let $\bar{\omega} \equiv \mu_{\ell} \omega_{\ell}+\mu_{h} \omega_{h}$ denote the mean income.

The government uses a proportional tax, $t \in[0,1]$, to finance a lump-sum transfer to all citizens, $T \geq 0$. The utility of an individual with racial view $\rho$ who consumes $c$ and faces the government's racial position $r$ is described by $c-\frac{\alpha}{2}(r-\rho)^{2}$, where $\alpha>0$ is the same for all individuals. Thus, using the private budget constraint, $c=(1-t) \omega+T$, and the government budget constraint, $t \bar{\omega}=T$, we can represent the policy preferences of an individual of type $(\omega, \rho)$ by the following indirect utility function:

$$
u(t, r ; \omega, \rho) \equiv \omega+t(\bar{\omega}-\omega)-\frac{\alpha}{2}(r-\rho)^{2} .
$$

Let the policy space be $P=[0,1] \times \mathbb{R}$, with generic element $(t, r)$. The indifference curves of the four groups are depicted in the upper left panel of Figure 1.

In this economy, the collective choice of a public policy $(t, r)$ is made through electoral competition between endogenous political parties. We now turn to the description of the electoral competition side of the model.

\subsection{Political Parties and Elections}

The modelling of electoral competition we adopt is that of Levy (2004). We present that approach in the context of our paper, but refer the reader to her paper for an in-depth discussion of the basic assumptions, and to the appendix of the present paper for a more formal presentation of the concepts.

Each group of voters is represented by a single politician, labelled by $\theta \in$ $\Theta$, who is a perfect representative of her group, in that her policy preferences are given by (1). Politicians are unable to commit to campaign promises before the election, so that a politician running alone can only propose her ideal policy. The key assumption of Levy (2004) is, however, that politicians can credibly commit to a larger set of policies by forming political parties (or coalitions, to use the language of game theory): the set of policies which a party can commit to is the Pareto set of its members. Formally, a policy $(t, r) \in P$ is in the Pareto set of party $S \subseteq \Theta, P_{S}$, if there is no other policy $\left(t^{\prime}, r^{\prime}\right)$ such that $u\left(t^{\prime}, r^{\prime} ; \theta\right) \geq u(t, r ; \theta)$ for all $\theta \in S$ and $u\left(t^{\prime}, r^{\prime} ; \hat{\theta}\right)>u(t, r ; \hat{\theta})$ for some $\hat{\theta} \in S$.

The political game has two stages: 
1. Party formation: politicians get organized into political parties;

2. Electoral competition: parties compete in a winner-takes-all election.

The outcome of the first stage is then a partition of the set of politicians, $\Theta$, into a party structure, $\pi$. The elements of $\pi$, namely political parties, play the electoral-competition game in the second stage. We first study the electoral competition stage for a given party structure, before turning to the determination of the equilibrium party structure.

\section{Electoral Competition}

Formally, a party is a non-empty subset of $\Theta$. A party structure is a partition of $\Theta$ into parties. Let $\Pi$ be the set of party structures. The objective of this subsection is to define the set of equilibria of the electoral-competition game, should the competition commence from some arbitrary party structure $\pi \in \Pi$.

An electoral strategy (or platform) for party $S \in \pi$ is a policy choice $\left(t_{S}, r_{S}\right) \in P_{S} \cup\{\varnothing\}$, where $\varnothing$ means that the party proposes no policy (it does not run). In the case where no party runs for election, every politician receives a zero payoff. If at least one party runs, we assume that voters record their preferences sincerely over any list of candidate platforms, $\mathbf{p} \equiv$ $\left\{\left(t_{S}, r_{S}\right)\right\}_{S \in \pi}$, and that the election is by plurality rule with no abstention. The election outcome is then a fair lottery between the policies that get the largest vote share. ${ }^{4}$ Given a party structure $\pi \in \Pi$, a vector of electoral strategies $\mathbf{p}=\left\{\left(t_{S}, r_{S}\right)\right\}_{S \in \pi}$ is a $\pi$-equilibrium of the electoral-competition game if no party $S \in \pi$ can make all its members better-off by deviating to another platform $\left(t_{S}^{\prime}, r_{S}^{\prime}\right) \in P_{S} \cup\{\varnothing\}$.

In line with Levy (2004), we assume that if a party is indifferent between running and not running, it chooses not to run. We restrict ourselves to purestrategy equilibria that are partisan, in the sense that voters strictly prefer their party's platform (if their party proposes one) to any other party's platform. And to avoid repeatedly having to include the relevant qualification, we leave it as understood that any reference to $\pi$-equilibria is actually to pure-strategy partisan $\pi$-equilibria.

Any profile of electoral strategies induces an electoral outcome which, due to the possibility of a tie, may be a lottery between several policies. Let $\Delta P$ be the family of lotteries over the set of feasible policies, $P$. We finally denote by $\delta: \Pi \rightrightarrows \Delta P$ the correspondence which assigns to each partition $\pi$ the set of electoral outcomes $\delta(\pi) \subseteq \Delta P$ that may result in a $\pi$-equilibrium.

\footnotetext{
${ }^{4}$ Voters who are indifferent between several policies use a fair mixing device.
} 
Up to this point, we have taken the coalition structure as given. We now turn to party formation.

\section{Party Formation}

Politicians anticipate the outcome from the electoral-competition stage, as described above, when forming parties at the first stage. For any party structure $\pi$, however, there may exist multiple equilibria in the electoralcompetition game, and therefore multiple equilibrium outcomes $(\delta(\pi)$ may not be a singleton). Thus, $\pi$ may satisfy stability conditions for one electoral outcome but not for others. As a consequence, we will not study the stability of $\pi$ alone, but the stability of pairs $(\pi, \wp)$ satisfying $\wp \in \delta(\pi)$. We will refer to them as political states. Which of these should be considered as the set of equilibrium outcomes for the present model? The answer to this question depends on the stability requirements imposed on party structures. In this model, Levy (2004) uses a stability concept developed by Ray and Vohra (1997). Relegating a formal presentation of this concept to the appendix, we provide here the basic intuitions.

Let $\pi$ and $\pi^{\prime}$ be two party structures. $\pi^{\prime}$ is said to be induced from $\pi$ if $\pi^{\prime}$ is formed by breaking a party in $\pi$ into two. Now, let $S$ be a sub-coalition of a party in $\pi$. S is a deviator if it can induce some party structure $\pi^{\prime}$

from $\pi$. An immediate consequence of this definition is that there can be no deviators (and then no deviations) from the finest party structure $\pi^{0}$, which consists of four singletons. Put differently, a pair $\left(\pi^{0}, \wp\right)$ is regarded as stable whenever $\wp \in \delta\left(\pi^{0}\right)$. With this observation in mind, we can recursively define the sequential notion of blocking of Ray and Vohra (1997): $\left(\pi^{\prime}, \wp^{\prime}\right)$ is said to sequentially block $(\pi, \wp)$ if there exists a leading deviator in $\pi$ that can suggest a sequence of deviations towards $\left(\pi^{\prime}, \wp^{\prime}\right)$ such that $(i)\left(\pi^{\prime}, \wp^{\prime}\right)$ cannot be sequentially blocked; and (ii) at each intermediate step of the sequence of deviations, some coalition has an incentive to induce the next step, because all members of this coalition get a larger payoff with the final outcome $\left(\pi^{\prime}, \wp^{\prime}\right)$ than in that intermediate state.

We thus define equilibrium political states as follows.

Definition 1 An equilibrium political state (EPS) is a pair $\left(\pi^{*}, \wp^{*}\right) \in \Pi \times$ $\Delta P$ that satisfies the following conditions:

- $\wp^{*} \in \delta\left(\pi^{*}\right)$,

- there is no $(\pi, \wp) \in \Pi \times \Delta P$ that sequentially blocks $\left(\pi^{*}, \wp^{*}\right)$. 
Thus, an equilibrium situation is defined as one that meets two requirements: first, the public policy results from the electoral competition between existing political parties; second, in every existing party, politicians have no incentive to break up their party in order to favor different electoral outcomes.

We are now in a position to apply this political equilibrium concept to our economic environment.

\section{Analysis of Equilibrium Political States}

To highlight the impact of party formation on policy outcomes, we first focus on equilibria where candidates decide individually whether to run or not for elections, but where they do not have the possibility of forming parties. ${ }^{5}$ We then study the equilibria when candidates can form parties.

\subsection{Equilibria without Party Formation}

Most of our conclusions depend on the salience of the redistribution issue relative to the race issue. For our purposes, a useful measure of that saliency is:

$$
\eta \equiv \frac{\omega_{h}-\omega_{\ell}}{\alpha\left(\rho^{+}-\rho^{-}\right)^{2}}
$$

The saliency of the redistribution issue is affected by three factors: income inequality, as measured by the difference between income levels, heterogeneity in the views on racism, and the parameter $\alpha$ which measures the intensity of the trade-off between ideological and economic positions. A low value of $\eta$ corresponds to the case where the difference in endowments is low compared to the difference in racial views, and/or to the case where individuals care a lot more about ideology than about redistribution (large value of $\alpha$ ). In other words, the ideological dimension is very salient while the economic dimension has low saliency. More precisely, if $\eta<1 /\left(2 \mu_{\ell}\right)$, ideology matters more than taxation for all voters, in the following sense: all individuals prefer any policy with their most favored racial view to any policy with the opposite racial view, whatever the tax rates in both policies:

$$
u\left(t, \rho^{i} ; \theta_{k}^{i}\right)>u\left(t^{\prime}, \rho^{j} ; \theta_{k}^{i}\right)
$$

for all $0 \leq t, t^{\prime} \leq 1, k=\{\ell, h\}, \quad i, j \in\{-,+\}$ and $i \neq j$. This case is depicted in the upper-right panel of Figure 1.

\footnotetext{
${ }^{5}$ This corresponds to the citizen candidate model of Osborne and Slivinski (1996). Besley and Coate (1997) also study candidate entry but assume that citizens vote strategically.
} 


\section{[FIGURE 1 HERE]}

On the other hand, if $\eta>1 /\left(2 \mu_{h}\right)$, taxation is more salient than ideology in that all individuals prefer any policy with their most favored taxation component to any policy with the least preferred taxation component, whatever the racism degree of both policies:

$$
u\left(t^{k}, r ; \theta_{k}^{i}\right)>u\left(1-t^{k}, r^{\prime} ; \theta_{k}^{i}\right),
$$

for all $k=\{\ell, h\}, \quad t^{l}=1, t^{h}=0, \rho^{-} \leq r, r^{\prime} \leq \rho^{+}, \quad i, j \in\{-,+\}$ and $i \neq j$. Indifference curves corresponding to that case are drawn in the lower-left panel of Figure 1.

In the intermediate case where $1 /\left(2 \mu_{\ell}\right)<\eta<1 /\left(2 \mu_{h}\right)$, poor people care more about ideology while rich people care more about taxation (see the lower-right panel of Figure 1):

$$
\text { for all } i, j \in\left\{\begin{aligned}
&\{-,+\} \text { and } i \neq j, \text { we have } \\
&\left\{\begin{array}{c}
u\left(t, \rho^{i} ; \theta_{\ell}^{i}\right)>u\left(t^{\prime}, \rho^{j} ; \theta_{\ell}^{i}\right) \text {, for all } 0 \leq t, t^{\prime} \leq 1, \\
u\left(0, r ; \theta_{h}^{i}\right)>u\left(1, r^{\prime} ; \theta_{h}^{i}\right) \text {, for all } \rho^{-} \leq r, r^{\prime} \leq \rho^{+} .
\end{array}\right.
\end{aligned}\right.
$$

The reason why the threshold value of $\eta$ is a function of $\mu_{\ell}$ is the following. Increasing the proportion of low income people decreases the average income in the economy, which in turn means that poor people gain less from taxation (making ideology relatively more important for them) while rich people lose more from taxation (making this issue relatively more salient for them). Also, our assumption that there are more poor than rich people $\left(\mu_{\ell}>1 / 2\right)$ results in an average income closer to the income of the poor than of the rich, so that the amount poor people gain from taxation is always lower (in absolute value) than the amount rich people lose from taxation. This explains why, whatever the value of $\eta$, there is no case where poor people care more about taxation while rich people care more about ideology.

This discussion about the meaning of $\eta$ will help understand the following Proposition, which states formally that the only equilibrium without party formation is the non-racist policy coupled with income confiscation. ${ }^{6}$

Proposition 1 Let $\wp^{0} \in \Delta P$ be defined by: $\wp^{0}\left(1, \rho^{-}\right)=1$. If $\eta<\frac{1}{2 \mu_{\ell}}$ or $\eta>\frac{1}{2 \mu_{h}}$, then $\wp^{0}$ is the unique $\pi^{0}$-equilibrium. If $\eta \in\left(\frac{1}{2 \mu_{\ell}}, \frac{1}{2 \mu_{h}}\right)$, then there is no $\pi^{0}$-equilibrium.

\footnotetext{
${ }^{6}$ The proofs of all Propositions are relegated to the Appendix.
} 
The intuition for this result is the following. Individual candidates can only commit to their most preferred policy, so we only have to consider four policies. Whatever the value of $\eta$, policy $\left(1, \rho^{-}\right)$is always majority preferred to $\left(0, \rho^{-}\right)$(with the support of all poor individuals) and to $\left(1, \rho^{+}\right)$ (with the support of all non-racist voters). When $\eta$ is low, all non-racist voters prefer $\left(1, \rho^{-}\right)$to $\left(0, \rho^{+}\right)$, while if $\eta$ is high, all poor people prefer $\left(1, \rho^{-}\right)$to $\left(0, \rho^{+}\right)$. In both cases, $\left(1, \rho^{-}\right)$is a Condorcet winner among the four most preferred policies, and at equilibrium the candidate representing poor non-racist individuals proposes this policy. On the other hand, if $\eta$ has an intermediate value, all voters except the poor non-racist prefer $\left(0, \rho^{+}\right)$ to $\left(1, \rho^{-}\right)$. Since $\left(0, \rho^{+}\right)$is beaten at the majority by $\left(1, \rho^{+}\right)$, there is no Condorcet winner and no equilibrium with only one candidate running. We further show in the Appendix that there is no equilibrium with more than one candidate running, whatever the value of $\eta \cdot{ }^{7}$

Proposition 1 has established that no racist policy can emerge at equilibrium in the absence of party formation. In the next subsection, we investigate whether and how party formation may lead to racist policies $\left(r>\rho^{-}\right)$.

\subsection{Equilibria with Endogenous Parties}

In the previous subsection, we have shown that only the poor non-racist politician's ideal policy may be implemented at equilibrium in the absence of party formation. We stress this result not for its empirical plausibility, but rather because it shows that party formation is needed to obtain political equilibria with racist policies in our model. Party formation is a necessary but not sufficient condition for the emergence of a different policy: equilibria where parties form but where the equilibrium policy remains the same as without parties exist in our framework. These situations are not interesting for our purpose, which is to find the set of policies that can only emerge when parties form. We then rather concentrate on EPS in which parties are effective in the following sense (Levy, 2004): An EPS $(\pi, \wp)$ involves effective parties if, and only if, $\wp \notin \delta\left(\pi^{0}\right)$.

We now show that there indeed exist EPS with racist policies. To favour the emergence of policies other than the one most preferred by the poor

\footnotetext{
${ }^{7}$ We do not consider the cases where $\eta=1 /\left(2 \mu_{\ell}\right)$ or $\eta=1 /\left(2 \mu_{h}\right)$ in this paper for two reasons. First, these are zero-measure events. Second, allowing for these possibilities renders the proofs much longer and more convoluted, with no gain in economic intuition. We nevertheless point out that allowing for either case results in (knife-edged) distributions of types and lotteries $\wp$ such that $\wp \in \delta\left(\pi^{0}\right)$ and $\wp\left(0, \rho^{+}\right)>0$. For instance, if $\eta=1 /\left(2 \mu_{h}\right)$ and $\mu_{h}+\mu_{\ell}^{+} / 2=\mu_{\ell}^{-}+\mu_{\ell}^{+} / 2=1 / 2$, the equiprobable lottery between $\left(0, \rho^{+}\right)$and $\left(1, \rho^{-}\right)$ is an equilibrium.
} 
non-racist, it is natural to first look at partitions where the other types form parties, allowing them to enlarge the set of admissible (i.e., mutually beneficial) policies. Formally, let $\Pi_{\ell}^{-} \subset \Pi$ be the set of party structures $\pi$, $\pi \neq \pi^{0}$, such that $\left\{\theta_{\ell}^{-}\right\} \in \pi$, i.e., in which the poor non-racist politician stays on his own while other types coalesce into one or two parties. We then obtain the following proposition.

Proposition 2 For any $\eta>0$, there exists an $\operatorname{EPS}(\pi, \wp)$ such that $\pi \in \Pi_{\ell}^{-}$, and $\wp(t, r)>0$ for some policy $(t, r)$ with $r>\rho^{-}$.

This proposition shows that there is always room for a party to form and enable its members to escape the "tyranny" of the poor non-racist politician. But the existence of EPS with effective parties is not the sole implication of this proposition. Indeed, it also says that allowing for party formation guarantees the existence of an EPS in which a racist policy is implemented with positive probability.

The proof of this result runs as follows. We first show that the only non-racist policy other than $\left(1, \rho^{-}\right)$that can be proposed with $\Pi_{\ell}^{-}$is $\left(0, \rho^{-}\right)$, because non-racist policies with a positive tax rate do not belong to the Pareto set of any party that does not include the poor non-racist. We then show that no party can win outright with policy $\left(0, \rho^{-}\right)$, which establishes that, if an EPS with effective parties exists, it implies that $\wp(t, r)>0$ for some policy $(t, r)$ with $r>\rho^{-}$. We finally prove the existence of such EPS by showing that, if an EPS with effective parties does not exist for the partition consisting of three parties, then it surely exists for the partition where all politicians join a single party that runs against the poor non-racist candidate.

Proposition 2, however, does not exclude the existence of EPS in which non-racist policies (with $r=\rho^{-}$) are implemented. With this as motivation, we now look for conditions on the saliency index, $\eta$, under which only racist policies are implemented with positive probability in an EPS.

Taxation saliency influences equilibrium policies both at the electoral competition stage (for a given party structure) and at the party formation stage. Before stating the main result of this paper, we first illustrate from an intuitive viewpoint how issue saliency impacts the electoral competition stage, for a given party structure. We consider party structure $\pi^{1} \equiv\left\{\left\{\theta_{h}^{+}, \theta_{\ell}^{+}\right\},\left\{\theta_{\ell}^{-}\right\},\left\{\theta_{h}^{-}\right\}\right\}$, where a party made of both racist types competes against the two non-racist candidates. Racist politicians coalesce into one party because this enables them to enlarge the set of admissible platforms to all most racist policies, whatever their tax component (the Pareto set for the two racist politicians is made of policies $\left.\left(0 \leq t \leq 1, \rho^{+}\right)\right)$. The equilibrium policies with this party structure depend crucially on the relative 
salience of both issues. If taxation is very salient compared to ideology (i.e., if $\eta$ is high enough), the only EPS that emerge have the racist party running alone and proposing the most racist policy $\rho^{+}$together with some positive tax rate (that falls short of full income confiscation). ${ }^{8}$ The intuition for this result goes as follows. The racist party running alone is an EPS if none of the most preferred policies of the two non-racist politicians $\left(\left(0, \rho^{-}\right)\right.$and $\left.\left(1, \rho^{-}\right)\right)$ is preferred by both non-racists to the policy offered by the racist party. If taxation is very salient, the two non-racist politicians are too divided on the tax issue to agree on one of those two extreme non-racist policies.

On the other hand, if taxation is not very salient (i.e., if $\eta$ is low enough), no such EPS exists (because the two non-racists can agree on a unanimously preferred policy), but there may exist equilibria with the three parties running, so that the equilibrium consists of an equiproportional lottery between two non-racist policies with extreme taxation components and one most racist one with positive taxation. The link between issue saliency and this threepolicy lottery runs as follows. When the taxation issue is salient enough, the rich (resp. poor) racist feels closer to the policy most preferred by the rich (resp. poor) non-racist than by his fellow racist politician, so that, whatever the policy that the racist party proposes, at least one of the two racist politicians prefers the policy proposed by his fellow non-racist. This in turn means that the situation where the three parties run can not be a partisan equilibrium when $\eta$ is high enough. Alternatively, if the main dividing line is ideology, racist politicians can compromise and find a policy that they both prefer to the non-racist policies with extreme taxation. An equilibrium with the three parties winning may then exist.

The study of party structure $\pi^{1}$ illustrates how taxation saliency results in racist equilibrium policies at the electoral competition stage, by making it impossible for non-racists to coordinate and oppose the racist party policies. This in turn has an impact on the party formation stage, where candidates anticipate the bargaining power gained by racist politicians when they form a party together with at least one non-racist politician. Since racist politicians can credibly threaten to leave any such party whose proposal does not give them at least the utility level they obtain with the $\pi^{1}$ racist equilibrium, they can force non-racist fellow party members to compromise on racism.

These two channels through which a high taxation saliency feeds into more political power for the racist politicians constitute the driving forces behind the next proposition.

Proposition 3 Suppose $\mu_{h} \eta \geq 1$. There exists a strictly increasing threshold function $\bar{r}:(1 / 2,1) \rightarrow\left(\rho^{-}, \rho^{+}\right)$, with $\lim _{\mu \rightarrow 1} \bar{r}(\mu)=\rho^{+}$, such that the

\footnotetext{
${ }^{8}$ The precise statement and proof is given in Lemma 2 in the Appendix.
} 
following statement is true: If $\left(\pi^{*}, \wp^{*}\right)$ is an EPS with effective parties, then any policy $(t, r) \in P$ such that $\wp^{*}(t, r)>0$ satisfies $r \geq \bar{r}\left(\mu_{\ell}\right)$.

This proposition states formally the main result of the paper, namely that, when the tax issue is very salient, all EPS with effective parties exhibit a racist policy (in that $r>\rho^{-}$), while the minimum degree of racism of implemented policies increases with the proportion of poor in the citizenry. The intuition for the first part of this result is the one discussed previously. Taxation saliency favours racist policies through two channels. First, it divides poor and rich non-racist politicians, thus enabling successful agreements between racist politicians. Second, given that such agreements are possible, they endow racist politicians with a strong bargaining power (or threat of deviation) in parties made of both racist and non-racist members, thus forcing the latter to compromise and accept racist policies.

We now present the intuition as to why the minimum equilibrium degree of racism increases with the proportion of poor people. The key channel for this result is that the bargaining power of the poor racist politician increases with $\mu_{l}$. To see this, we look at the partition $\pi^{1}$ described above, where a party made of the two racist politicians competes against two non-racist parties. The proof of Lemma 2 shows that the upperbound on the equilibrium tax rate proposed by the racist party in $\pi^{1}$ is given by the constraint that the rich non-racists prefer the policy proposed by that party $\left(t, \rho^{+}\right)$to the mostpreferred policy of the poor non-racist $\left(1, \rho^{-}\right)$. An increase in $\mu_{l}$, causing a decrease of the average income $\bar{\omega}$, makes redistribution more costly to the rich non-racist, whose utility under policy $\left(1, \rho^{-}\right)$decreases so much that she is ready to accept a policy $\left(t, \rho^{+}\right)$with a larger $t$ from the racist party. This makes the poor racist politician better-off with partition $\pi^{1}$, and consequently raises her bargaining power in all partitions where racist candidates belong to the same party (i.e., partitions from which $\pi^{1}$ can be induced). This in turn increases the minimum degree of racism among all EPS.

The result described in Proposition 3 is important from a positive perspective: it says that, even if a majority of citizens is non-racist, an extreme race policy may be democratically chosen in a society where the income distribution is highly polarized. Indeed, our discussion of the parameter $\eta$ in Subsection 3.1 has shown that it increases with the difference between income levels. In the context of our model, Esteban and Ray (1994)'s polarization measure is strictly increasing in $\omega_{h}-\omega_{\ell}$ and $\mu_{h}$ (keeping $\mu_{h}<1 / 2$ ), which both have to be large for the above proposition to hold. ${ }^{9}$ Furthermore,

\footnotetext{
${ }^{9}$ In the context of our paper, polarization is given by

$$
\operatorname{Pol}_{\omega} \equiv\left[\left(1-\mu_{h}\right)^{1+\alpha} \mu_{h}+\mu_{h}^{1+\alpha}\left(1-\mu_{h}\right)\right]\left(\omega_{h}-\omega_{\ell}\right),
$$
}


Lemma 2 in the appendix formally shows that, under the same condition, there exists an infinity of EPS in which the extremist race policy $r=\rho^{+}$ is enforced with probability 1. However, a word of caution is in order. Although income polarization is conducive to the adoption of racist policies, there is no clear relationship between polarization and the degree of racism of all equilibrium policies. More precisely, if income polarization is large enough, Proposition 3 applies and all equilibrium policies are (more or less) racist. On the other hand, increasing $\mu_{h}$ increases polarization but decreases the lower bound on racism described in Proposition 3. In short, income polarization implies racist policies, but increasing polarization also opens the door to less racist policies.

\section{Concluding Remarks}

We develop a model where voters differ in their views about income redistribution and about ideology, with racism as an illustration. We assume that a majority of voters has lower-than-average income and favours full income taxation, and that the majority of voters hold non-racist views.

Electoral competition, modeled à la Levy (2004), takes place between an endogenously determined number of parties which propose platforms consisting of both an ideological and an economic dimension. We first show that, in a pure citizen-candidate model where parties are absent, the only equilibrium consists of the majority ideological (i.e., non-racist), full confiscation policy. We then show that allowing for the formation of political parties generates equilibria with minority ideological policies. Finally, our main result is that, if the economic issue is sufficiently salient compared to the ideological one, all equilibria consist of a racist policy, and that the lowest degree of racism of these policies increases with the proportion of poor people in the economy.

These results are consistent with the observation in many European countries of xenophobic parties and policies even though a majority of European voters does not hold such views. Moreover, our approach generates testable implications concerning the link between the ideological component of equilibrium policies and income distribution. Our model suggests that racist policies are more likely when the distribution of income is very polarized, in the sense of Esteban and Ray (1994). To the best of our knowledge, there is

no empirical study of the relationship between ideological policies (on issues such as racism, abortion, stem cell research or gun control) and polarization, but we hope that our model will inspire empirical testing.

with $\alpha \in\left(0, \alpha^{*}\right]$ where $\alpha^{*} \simeq 1.6$ (Theorem 1 in Esteban and Ray, 1994). 
We have chosen to concentrate on the impact of party formation on the equilibrium ideological policies. We could rather focus on the other dimension, namely the extent to which income redistribution prevails at equilibrium. With this perspective, our model helps answering the question as to "why the poor do not expropriate the rich". Our answer then complements that of Roemer (1998): only non expropriation policies emerge at equilibrium if ideology is salient enough.

Although framed in terms of ideology and redistribution, the model we develop is actually more general in the sense that its main ingredients can be found in other contexts. These ingredients are: people are heterogeneous along two dimensions and electoral competition à la Levy takes place over two dimensions. People have extreme preferences in the sense that there are only two most preferred policies on each dimension. Since policies are bundled (i.e., a political platform is a two-dimensional policy), we have four types of most preferred two-dimensional policies. Our main results can then be reinterpreted more generally. First, in the absence of parties, the only equilibrium policy is the Condorcet winner among the four most preferred policies (we show that it may happen that there is no Condorcet winner, in which case there is no equilibrium, even though there is always an issueby-issue, majority voting equilibrium). Second, allowing for the formation of parties generates equilibria with interior policies, even though not a single voter most prefers such policies. In that sense, political parties are the main vehicles for compromise in our model. Third, we give conditions over the saliency of issues that guarantee that the most preferred policy of the majority (on one issue) is never part of the equilibrium.

\section{Appendix}

\section{Preliminary Definitions}

We use the following notation:

$$
\begin{array}{rll}
\pi^{1} \equiv\left\{\left\{\theta_{h}^{+}, \theta_{\ell}^{+}\right\},\left\{\theta_{\ell}^{-}\right\},\left\{\theta_{h}^{-}\right\}\right\} & , & \pi^{2} \equiv\left\{\left\{\theta_{h}^{+}, \theta_{\ell}^{-}\right\},\left\{\theta_{\ell}^{+}\right\},\left\{\theta_{h}^{-}\right\}\right\} \\
\pi^{3} \equiv\left\{\left\{\theta_{h}^{+}, \theta_{h}^{-}\right\},\left\{\theta_{\ell}^{+}\right\},\left\{\theta_{\ell}^{-}\right\}\right\} & , & \pi^{4} \equiv\left\{\left\{\theta_{\ell}^{+}, \theta_{\ell}^{-}\right\},\left\{\theta_{h}^{+}\right\},\left\{\theta_{h}^{-}\right\}\right\} \\
\pi^{5} \equiv\left\{\left\{\theta_{\ell}^{+}, \theta_{h}^{-}\right\},\left\{\theta_{h}^{+}\right\},\left\{\theta_{\ell}^{-}\right\}\right\} & , & \pi^{6} \equiv\left\{\left\{\theta_{\ell}^{-}, \theta_{h}^{-}\right\},\left\{\theta_{h}^{+}\right\},\left\{\theta_{\ell}^{+}\right\}\right\} \\
\pi^{7} \equiv\left\{\left\{\theta_{h}^{+}, \theta_{\ell}^{+}, \theta_{\ell}^{-}\right\},\left\{\theta_{h}^{-}\right\}\right\} & , & \pi^{8} \equiv\left\{\left\{\theta_{h}^{+}, \theta_{\ell}^{+}, \theta_{h}^{-}\right\},\left\{\theta_{\ell}^{-}\right\}\right\} \\
\pi^{9} \equiv\left\{\left\{\theta_{h}^{+}, \theta_{\ell}^{+}\right\},\left\{\theta_{\ell}^{-}, \theta_{h}^{-}\right\}\right\} & , & \pi^{10} \equiv\left\{\left\{\theta_{h}^{+}, \theta_{\ell}^{-}, \theta_{h}^{-}\right\},\left\{\theta_{\ell}^{+}\right\}\right\} \\
\pi^{11} \equiv\left\{\left\{\theta_{h}^{+}, \theta_{\ell}^{-}\right\},\left\{\theta_{h}^{-}, \theta_{\ell}^{+}\right\}\right\} & , & \pi^{12} \equiv\left\{\left\{\theta_{h}^{+}, \theta_{h}^{-}\right\},\left\{\theta_{\ell}^{+}, \theta_{\ell}^{-}\right\}\right\} \\
\pi^{13} \equiv\left\{\left\{\theta_{\ell}^{+}, \theta_{\ell}^{-}, \theta_{h}^{-}\right\},\left\{\theta_{h}^{+}\right\}\right\} & , & \pi^{14} \equiv\left\{\left\{\theta_{h}^{+}, \theta_{h}^{-}, \theta_{\ell}^{-}, \theta_{h}^{+}\right\}\right\}
\end{array}
$$


For each $S \subseteq \Theta$, and any policy $(t, r) \in P$, define the sets $P_{S}(t, r)$, $\bar{P}_{S}(t, r), I(t, r)$, and $\bar{I}(t, r)$ as

$$
\begin{aligned}
P_{S}(t, r) & \equiv\left\{\left(t^{\prime}, r^{\prime}\right) \in P_{\left\{\theta_{h}^{+}, \theta_{h}^{-}, \theta_{\ell}^{-}, \theta_{h}^{+}\right\}}: u\left(t^{\prime}, r^{\prime}, \theta\right)>u(t, r, \theta), \forall \theta \in S\right\} \\
\bar{P}_{S}(t, r) & \equiv P_{S}(t, r) \cap P_{S} \\
I_{S}(t, r) & \equiv\left\{\left(t^{\prime}, r^{\prime}\right) \in P_{\left\{\theta_{h}^{+}, \theta_{h}^{-}, \theta_{\ell}^{-}, \theta_{h}^{+}\right\}}: u\left(t^{\prime}, r^{\prime}, \theta\right)=u(t, r, \theta), \forall \theta \in S\right\} \\
\bar{I}_{S}(t, r) & \equiv I_{S}(t, r) \cap P_{S} .
\end{aligned}
$$

\section{The Model of Party Formation}

We first define formally the equilibrium concept used for the second-stage game, and then the notion of sequential blocking in the context of our paper.

\section{$\pi$-equilibria}

Let $\pi \in \Pi$ be the party structure. Given any party $S^{\prime}$ and any profile of electoral strategies $\mathbf{p} \equiv\left\{\left(t_{S}, r_{S}\right)\right\}_{S \in \pi}$, let $V_{S^{\prime}}(\mathbf{p})$ denote that party's realized vote share. The election outcome is then a fair lottery between the policies in $W(\mathbf{p}) \equiv\left\{\left(t_{S}, r_{S}\right): S \in \arg \max _{S^{\prime} \in \pi} V_{S^{\prime}}(\mathbf{p})\right\}$. As a consequence, the expected utility of politician $\theta$ resulting from a profile of strategies $\mathbf{p}$ is given by

$$
U(\mathbf{p}, \theta) \equiv \frac{1}{|W(\mathbf{p})|} \sum_{\left(t_{S}, r_{S}\right) \in W(\mathbf{p})} u\left(t_{S}, r_{S} ; \theta\right)
$$

if there is at least one party $S \in \pi$ such that $\left(t_{S}, r_{S}\right) \neq \varnothing$, and $U(\mathbf{p}, \theta)=0$ otherwise.

Given a party structure $\pi \in \Pi$, a vector of electoral strategies $\mathbf{p}=$ $\left\{\left(t_{S}, r_{S}\right)\right\}_{S \in \pi}$ is a $\pi$-equilibrium of the electoral-competition game if, for all $S \in \pi$, there is no $\left(t_{S}^{\prime}, r_{S}^{\prime}\right) \in P_{S},\left(t_{S}^{\prime}, r_{S}^{\prime}\right) \neq\left(t_{S}, r_{S}\right)$, that satisfies

$$
U\left(\left(t_{S}^{\prime}, r_{S}^{\prime}\right), \mathbf{p}_{-S} ; \theta\right) \geq U\left(\left(t_{S}, r_{S}\right), \mathbf{p}_{-S} ; \theta\right)
$$

for all $\theta \in S$, with at least one strict inequality. Note that, following Levy (2004), we restrict attention to pure-strategy equilibria.

\section{Sequential Blocking}

Consider $\pi \in \Pi$, and suppose that an equilibrium political state (EPS, for short) has already been defined for all party structures that are refinements of $\pi$. Let $\wp \in \delta(\pi)$. $\left(\pi^{\prime}, \wp^{\prime}\right)$ is said to sequentially block $(\pi, \wp)$ if there exists a sequence $\left\{\left(\pi^{1}, \wp^{1}\right), \ldots,\left(\pi^{m}, \wp^{m}\right)\right\}$ such that: 
1. $\left(\pi^{1}, \wp^{1}\right)=(\pi, \wp),\left(\pi^{m}, \wp^{m}\right)=\left(\pi^{\prime}, \wp^{\prime}\right)$ and for every $j=2, \ldots, m$, there is a deviator $S^{j}$ that induces $\pi^{j}$ from $\pi^{j-1}$. Moreover, for every $j$, $\wp^{j} \in \delta\left(\pi^{j}\right)$.

2. $\left(\pi^{\prime}, \wp^{\prime}\right)$ is an EPS.

3. $\left(\pi^{j}, \wp^{j}\right)$ is not an EPS for any $\wp^{j} \in \delta\left(\pi^{j}\right)$ and $j=2, \ldots, m-1$.

4. for all $j=1, \ldots, m-1$, and $\theta \in S^{j}$ :

$$
\sum_{(t, r): \wp^{\prime}(t, r)>0} \wp^{\prime}(t, r) u(t, r ; \theta)>\sum_{(t, r): \wp^{j}(t, r)>0} \wp^{j}(t, r) u(t, r ; \theta) .
$$

\section{Proof of Proposition 1}

(i) Assume that $\eta<1 /\left(2 \mu_{l}\right)$. We treat sequentially the cases where $4,3,2$ and 1 parties run at equilibrium.

(i a) 4 parties running. Our assumptions on $\mu_{j}^{i}(i \in\{-,+\}, j \in\{l, h\})$ rule out the case where the four parties tie when running.

(i b) 3 parties running. If either $\theta_{h}^{-}$or $\theta_{l}^{-}$does not run, our assumption that $\mu^{-}>1 / 2$ makes it impossible for the three running parties to tie for victory. If $\theta_{l}^{+}$does not run, $\theta_{l}^{-}$prefers not to run and obtain policy $\left(0, \rho^{-}\right)$ for sure to running and obtaining an equiprobable lottery between $\left(0, \rho^{+}\right)$, $\left(1, \rho^{-}\right)$and $\left(0, \rho^{-}\right)$. Similarly, if $\theta_{h}^{+}$does not run, $\theta_{h}^{-}$prefers not to run and obtain policy $\left(1, \rho^{-}\right)$for sure to running and obtaining an equiprobable lottery between $\left(1, \rho^{+}\right),\left(1, \rho^{-}\right)$and $\left(0, \rho^{-}\right)$. Hence, there is no equilibrium with 3 parties running.

(i c) 2 parties running. Observe that binary majority voting over the set of the four most preferred policies gives the following transitive social order: $\left(1, \rho^{-}\right) \succ\left(0, \rho^{-}\right) \succ\left(1, \rho^{+}\right) \succ\left(0, \rho^{+}\right)$where $\left(t^{\prime}, r^{\prime}\right) \succ(t, r)$ means that a strict majority of voters strictly prefer $\left(t^{\prime}, r^{\prime}\right)$ to $(t, r)$. It is then impossible for any two parties to tie for victory.

(i d) 1 party running. Given the transitive social order described above, policy $\left(1, \rho^{-}\right)$is a Condorcet winner among the four most preferred policies, and thus no party can enter and win when $\theta_{l}^{-}$runs alone, and no other party can run alone, otherwise $\theta_{l}^{-}$would enter and win. Hence, $\wp^{0}$ is the unique equilibrium.

(ii) The case where $\eta>1 /\left(2 \mu_{h}\right)$ is proved in like manner.

(iii) Assume that $1 /\left(2 \mu_{l}\right)<\eta<1 /\left(2 \mu_{h}\right)$.

(iii a) 4 parties running. Same argument as in (i a) above. 
(iii b) 3 parties running. If either $\theta_{h}^{-}$or $\theta_{h}^{+}$does not run, our assumption that $\mu_{l}^{-}>\mu_{l}^{+}$makes it impossible for the three running parties to tie for victory. If $\theta_{l}^{-}$does not run, option $\left(0, \rho^{-}\right)$wins for sure since $\mu^{-}>1 / 2$. If $\theta_{l}^{+}$does not run, $\theta_{l}^{-}$prefers not to run and obtain policy $\left(0, \rho^{-}\right)$for sure to running and obtaining an equiprobable lottery between $\left(0, \rho^{+}\right),\left(1, \rho^{-}\right)$and $\left(0, \rho^{-}\right)$. Hence, there is no equilibrium with 3 parties running.

(iii c) 2 parties running. Unlike in cases (i) and (ii) above, binary majority voting over the set of the four most preferred policies does not generate a transitive social order. We nevertheless have that whatever the two policies $\left(t_{i}, r_{i}\right) \in\{0,1\} \times\left\{\rho^{-}, \rho^{+}\right\}, i=1,2$ with $\left(t_{1}, r_{1}\right) \neq\left(t_{2}, r_{2}\right)$, a strict majority of voters strictly prefer $\left(t_{1}, r_{1}\right)$ to $\left(t_{2}, r_{2}\right)$ or the opposite. It is then impossible for any two parties to tie for victory.

(iii d) 1 party running. Given that binary majority voting over the set of the four most preferred policies is not transitive, there is no Condorcet winner among this set, and whatever party runs may be defeated by at least one entrant. Hence, there is no equilibrium with 1 party running, and $\delta\left(\pi^{0}\right)=\emptyset$.

\section{Proof of Proposition 2}

First of all, note that $\Pi_{\ell}^{-}=\left\{\pi^{j}\right\}_{j=1,3,5,8}$. Let $E_{j}, j \in\{1,3,5,8\}$, be the (possibly empty) set of values of $\eta$ such that there exists an EPS $\left(\pi^{j}, \wp\right)$ with $\wp \neq \wp^{0}$. We now make a useful claim.

Claim: Suppose $\eta \in E_{j}, j \in\{1,3,5,8\}$. Then for any $\operatorname{EPS}\left(\pi^{j}, \wp^{j}\right)$, there exists a policy $\left(t^{j}, r^{j}\right)$ such that $r^{j}>\rho^{-}$and $\wp^{j}\left(t^{j}, r^{j}\right)>0$.

Proof: From the definition of $E_{j}$, it suffices to show that, for every $j \in\{1,3,5,8\}$, there is no party offering policy $\left(0, \rho^{-}\right)$and winning with probability 1 in a $\pi^{j}$-equilibrium (if $t \in(0,1)$, then $\left(t, \rho^{-}\right) \notin \bar{P}_{S}, \forall S \in \pi^{j}$ ). Consider party structure $\pi^{1}$. In this structure, $\left(0, \rho^{-}\right)$only belongs to the Pareto set of $\left\{\theta_{\ell}^{+}\right\}$. But it can never win for sure by offering that policy. Indeed, this would mean that it runs alone, which is impossible in a $\pi^{1}$ equilibrium: $\left\{\theta_{\ell}^{-}\right\}$could deviate and offer $\left(1, \rho^{-}\right)$, thus enforcing its ideal policy. A completely similar argument applies to $\pi^{3}, \pi^{5}$, and $\pi^{8}$.

It results from the claim that Proposition 2 holds if $\cup_{j=1,3,5,8} E_{j}=\mathbb{R}_{+}$. We now show that $\eta \notin \cup_{j=1,3,5} E_{j}$ implies $\eta \in E_{8}$, thus proving the result. To see this, note that, when $\eta \notin \cup_{j=1,3,5} E_{j}$, a deviation from structure $\pi^{8}$ is either impossible $\left(\delta\left(\pi^{j}\right)=\emptyset, \forall j=1,3,5\right)$, or leads to policy $\left(1, \rho^{-}\right)$with probability 1. As $\bar{P}_{\left\{\theta_{h}^{+}, \theta_{\ell}^{+}, \theta_{h}^{-}\right\}}\left(1, \rho^{-}\right) \neq \emptyset$, any $\left(\pi^{8}, \wp\right)$ satisfying $\wp(t, r)=1$ for some $(t, r) \in \bar{P}_{\left\{\theta_{h}^{+}, \theta_{\ell}^{+}, \theta_{h}^{-}\right\}}\left(1, \rho^{-}\right) \subseteq \delta\left(\pi^{8}\right)$ is therefore an EPS in such a situation. Since $r>\rho^{-}$for all $(t, r) \in \bar{P}_{\left\{\theta_{h}^{+}, \theta_{\ell}^{+}, \theta_{h}^{-}\right\}}\left(1, \rho^{-}\right), \eta$ must belong to 
$E_{8}$.

\section{Proof of Proposition 3}

Before we proceed to a proof of Proposition 3, the following preliminary lemmas are useful.

Lemma 1 Let $\eta>\frac{1}{2 \mu_{h}}$. For every $j \in\{2,3,4,6,10,12\},\left(\pi^{j}, \wp\right)$ is an EPS if and only if $\wp\left(1, \rho^{-}\right)=1$.

Proof: Suppose $\eta>1 / 2 \mu_{h}$.

When $j=2,4,6$, the lemma is obvious: if the equilibrium outcome differs from $\left(1, \rho^{-}\right)$, then politician $\theta_{\ell}^{-}$can profitably deviate to $\pi^{0}$, thereby enforcing her ideal policy. Moreover, as $\left(1, \rho^{-}\right)$is a Condorcet winner in the set of ideal policies when $\eta>\frac{1}{2 \mu_{h}}$, it is easy to see that there is no profitable deviation when the two-member party runs alone and offers $\left(1, \rho^{-}\right)$.

Let us turn to party structure $\pi^{3}$. From the assumption that $\mu_{\ell}^{-}>\mu_{\ell}^{+}$, there cannot be a $\pi^{3}$-equilibrium in which the three parties are running (a tie is impossible). Moreover, for every policy $(t, r) \in P_{\left\{\theta_{h}^{+}, \theta_{h}^{-}\right\}},\left(1, \rho^{-}\right)$is a Condorcet winner in $\left\{\left(1, \rho^{-}\right)\right\} \cup P_{\left\{\theta_{h}^{+}, \theta_{h}^{-}\right.}$, and a majority of citizens strictly prefer $\left(1, \rho^{+}\right)$to $(t, r)$. As a consequence, there is no $\pi^{3}$-equilibrium in which two parties choose to run, and $\left(1, \rho^{-}\right)$is the unique $\pi^{3}$-equilibrium outcome.

Consider now $\pi^{10}$. Here again, there cannot be a tie between $\left\{\theta_{h}^{+}, \theta_{\ell}^{-}, \theta_{h}^{-}\right\}$ and $\left\{\theta_{\ell}^{+}\right\}$. As $\bar{P}_{\left\{\theta_{h}^{+}, \theta_{\ell}^{-}, \theta_{h}^{-}\right\}}\left(1, \rho^{+}\right)$is non-empty, $\left\{\theta_{\ell}^{+}\right\}$running alone cannot be a $\pi^{10}$-equilibrium. What about $\left\{\theta_{h}^{+}, \theta_{\ell}^{-}, \theta_{h}^{-}\right\}$running alone? It is easy to check that there is an infinity of policies $(t, r)$ such that $\left\{\theta_{h}^{+}, \theta_{\ell}^{-}, \theta_{h}^{-}\right\}$ running alone and offering $(t, r)$ is a $\pi^{10}$-equilibrium, among which is $\left(1, \rho^{-}\right)$. However, as politician $\left\{\theta_{\ell}^{-}\right\}$can induce $\pi^{3}$ (and then $\left.\left(1, \rho^{-}\right)\right),\left(\pi^{10}, \wp\right)$ is an EPS if and only if $\wp\left(1, \rho^{-}\right)=1$.

Finally, $\left(\pi^{12},\left(1, \rho^{-}\right)\right)$is the unique EPS involving $\pi^{12}$. To see this, note first that such an EPS must involve party $\left\{\theta_{\ell}^{+}, \theta_{\ell}^{-}\right\}$running alone $\left(\mu_{\ell}>\mu_{h}\right)$. As $\bar{P}_{\left\{\theta_{\ell}^{+}, \theta_{\ell}^{-}\right\}}(t, r)=P_{\left\{\theta_{\ell}^{+}, \theta_{\ell}^{-}\right\}}$for any $(t, r) \in P_{\left\{\theta_{h}^{+}, \theta_{h}^{-}\right\}},\left(1, \rho^{-}\right) \in \delta\left(\pi^{12}\right)=$ $P_{\left\{\theta_{\ell}^{+}, \theta_{\ell}^{-}\right\}}$. Moreover, if the policy offered by party $\left\{\theta_{\ell}^{+}, \theta_{\ell}^{-}\right\}$differs from $\left(1, \rho^{-}\right)$, politician $\theta_{\ell}^{-}$can profitably break up her party and then induce $\pi^{3}$. Our previous results show that no political state can sequentially block $\left(\pi^{12}, \wp^{\circ}\right)$, thus proving that $\left(\pi^{12}, \wp^{\circ}\right)$ is the only EPS involving $\pi^{12}$. This completes the proof of Lemma 1. 
Lemma 2 If $\mu_{h} \eta \geq 1$, then

(i) $\wp \in \delta\left(\pi^{1}\right)$ and $\wp(t, r)>0$ imply that $(t, r) \in P_{\left\{\theta_{h}^{+}, \theta_{\ell}^{+}\right\}}$, and

(ii) Any $\left(\pi^{1}, \wp\right)$ with $\wp\left(t, \rho^{+}\right)=1$ and $t \in\left(\bar{t}_{2}, \bar{t}_{1}\right)$, where

$$
\bar{t}_{1} \equiv 1-\frac{1}{2 \eta \mu_{\ell}}, \text { and } \bar{t}_{2} \equiv 1-\frac{1}{2 \eta \mu_{h}},
$$

is an $E P S$.

Proof: When $2 \mu_{\ell} \mu_{h} \eta\left(>\mu_{h} \eta\right) \geq 1$, the set $P_{\left\{\theta_{h}^{+}\right\}}\left(0, \rho^{-}\right) \cap P_{\left\{\theta_{\ell}^{+}\right\}}\left(1, \rho^{-}\right)$ is empty. As a consequence, whenever the three parties run, at least one member of party $\left\{\theta_{h}^{+}, \theta_{\ell}^{+}\right\}$prefers the policy offered by a rival party to that offered by her own party. It is therefore impossible for a $\pi^{1}$-equilibrium in which the three parties run to be partisan when $\mu_{h} \eta \geq 1$.

Given the party structure $\pi^{1}$, statement (i) is not true only when either $\left\{\theta_{h}^{-}\right\}$or $\left\{\theta_{\ell}^{-}\right\}$win with a positive probability. We now show that this is not possible when $\eta>\frac{1}{2 \mu_{h} \mu_{\ell}}$.

As a majority of citizens strictly prefer $\left(1, \rho^{-}\right)$to $\left(0, \rho^{-}\right)$, the strategy profiles $\left\{\varnothing,\left(1, \rho^{-}\right),\left(0, \rho^{-}\right)\right\}$and $\left\{\varnothing, \varnothing,\left(0, \rho^{-}\right)\right\}$cannot be $\pi^{1}$-equilibria.

Now, suppose that a profile of the form $\left\{\left(t, \rho^{+}\right),\left(1, \rho^{-}\right), \varnothing\right\}$ is a $\pi^{1}$ equilibrium. For this equilibrium to be partisan, politician $\theta_{\ell}^{+}$must prefer $\left(t, \rho^{+}\right)$to $\left(1, \rho^{-}\right)$or, equivalently, $t>\bar{t}_{2}$, and there must be a tie between the two running parties (voters of type $\theta_{h}^{-}$must be indifferent): $\wp\left(t, \rho^{+}\right)=$ $\wp\left(1, \rho^{-}\right)=1 / 2$. Then, by continuity, party $\left\{\theta_{h}^{+}, \theta_{\ell}^{+}\right\}$can improve upon $\wp$ by offering a platform $\left(t-\varepsilon, \rho^{+}\right)$with $\varepsilon$ arbitrarily small. Doing so, it woos $\theta_{h}^{-}$-voters away from party $\left\{\theta_{\ell}^{-}\right\}$and makes all its members strictly betteroff. As a consequence, $\left\{\left(t, \rho^{+}\right),\left(1, \rho^{-}\right), \varnothing\right\}$ is not a $\pi^{1}$-equilibrium. We could prove in like manner that a profile of the form $\left\{\left(t, \rho^{+}\right), \varnothing,\left(0, \rho^{-}\right)\right\}$cannot be a $\pi^{1}$-equilibrium.

Finally, $\left\{\varnothing,\left(1, \rho^{-}\right), \varnothing\right\}$ cannot be a $\pi^{1}$-equilibrium. Indeed, party $\left\{\theta_{h}^{+}, \theta_{\ell}^{+}\right\}$ can enter and win with the platform $\left(t-\varepsilon, \rho^{+}\right)$described above. This completes the proof of (i).

Let us now turn to statement (ii). From the above argument, we know that if $\wp \in \delta\left(\pi^{1}\right)$, then there exists $(t, r) \in P_{\left\{\theta_{h}^{+}, \theta_{\ell}^{+}\right\}}$such that $\wp(t, r)=1$. This corresponds to a platform profile $\left\{\left(t, \rho^{+}\right), \varnothing, \varnothing\right\}$. But this platform is a $\pi^{1}$-equilibrium only if parties $\left\{\theta_{\ell}^{-}\right\}$and $\left\{\theta_{h}^{-}\right\}$have no profitable deviations. As $\mu^{-}>1 / 2$, offering $\left(1, \rho^{-}\right)$is a profitable deviation for $\left\{\theta_{\ell}^{-}\right\}$whenever $\theta_{h}^{-}$-voters prefer $\left(1, \rho^{-}\right)$to $\left(t, \rho^{+}\right)$or, equivalently, $t \geq \bar{t}_{1}$ (the inequality may be strict depending on the distribution of types). Similarly, as $\mu_{\ell}>1 / 2$, offering $\left(1, \rho^{-}\right)$is a profitable deviation for $\left\{\theta_{\ell}^{-}\right\}$whenever $\theta_{\ell}^{+}$-voters prefer $\left(1, \rho^{-}\right)$to $\left(t, \rho^{+}\right)$or, equivalently, $t \leq \bar{t}_{2}$. 
Finally, party $\left\{\theta_{h}^{-}\right\}$cannot profitably deviate if $\theta_{\ell}^{-}$-voters strictly prefer $(t, r)$ to $\left(0, \rho^{-}\right)$or, equivalently,

$$
t>\bar{t}_{3} \equiv \frac{1}{2 \eta \mu_{h}} .
$$

As $\bar{t}_{2}=\max \left\{\bar{t}_{2}, \bar{t}_{3}\right\}<\bar{t}_{1}$ when $\mu_{h} \eta \geq 1,\left\{\left(t, \rho^{+}\right), \varnothing, \varnothing\right\}$ is a $\pi^{1}$-equilibrium whenever $t \in\left(\bar{t}_{2}, \bar{t}_{1}\right)$. Furthermore, $\left(\pi^{1}, \wp\right)$ is an EPS since neither $\theta_{h}^{+}$nor $\theta_{\ell}^{+}$ can profitably induce $\pi^{0}$ when $t>\bar{t}_{2}$.

Lemma 3 Suppose $2 \mu_{h} \eta>1$ and let $\bar{r} \equiv \mu_{\ell} \rho^{+}+\mu_{h} \rho^{-}$. Then $\left(\pi^{5}, \wp\right)$ is an EPS whenever $\wp(t, \bar{r})$ for some $t \in\left(\bar{t}_{4}, \bar{t}_{5}\right)$, where

$$
\bar{t}_{4} \equiv 1-\frac{1-\mu_{h}^{2}}{2 \mu_{h} \eta}, \text { and } \bar{t}_{5} \equiv 1-\frac{\mu_{\ell}}{2 \eta} .
$$

Moreover, $\left(\pi^{5}, \wp\right)$ is an EPS only if $\wp(t, \bar{r})=1$ for some $t \in\left[\bar{t}_{4}, \bar{t}_{5}\right]$.

Proof: Our assumptions on the distribution of citizens' types $\left(\mu_{\ell}>1 / 2\right.$ and $\left.\mu^{-}>1 / 2\right)$ do not allow $\pi^{5}$-equilibria of the form $\left\{(t, r),\left(0, \rho^{+}\right),\left(1, \rho^{-}\right)\right\}$.

As any $(t, r) \in \bar{P}_{\left\{\theta_{\ell}^{+}, \theta_{h}^{-}\right\}}\left(1, \rho^{-}\right) \neq \emptyset$ is preferred to $\left(1, \rho^{-}\right)$by $\theta_{h}^{+}$-voters, strategy profiles of the form $\left\{(t, r), \varnothing,\left(1, \rho^{-}\right)\right\}$and $\left\{\varnothing, \varnothing,\left(1, \rho^{-}\right)\right\}$cannot be $\pi^{5}$-equilibria. Similarly, $(t, r) \in \bar{P}_{\left\{\theta_{\ell}^{+}, \theta_{h}^{-}\right\}}\left(1, \rho^{-}\right)$is preferred to $\left(0, \rho^{+}\right)$ by $\theta_{\ell}^{-}$-voters, so that strategy profiles of the form $\left\{(t, r),\left(0, \rho^{+}\right), \varnothing\right\}$ and $\left\{\varnothing,\left(0, \rho^{+}\right), \varnothing\right\}$ cannot be $\pi^{5}$-equilibria.

Moreover, $\left\{\varnothing,\left(0, \rho^{+}\right),\left(1, \rho^{-}\right)\right\}$is not a $\pi^{5}$-equilibrium since $\left\{\theta_{\ell}^{-}\right\}$would win for sure.

Thus, only profiles of the form $\{(t, r), \varnothing, \varnothing\}$ are candidate to be $\pi^{5}$ equilibria. Noting that

$$
\bar{P}_{\left\{\theta_{\ell}^{+}, \theta_{h}^{-}\right\}}\left(1, \rho^{-}\right)=\left\{(t, \bar{r}): t \in\left(\bar{t}_{4}, \bar{t}_{5}\right)\right\},
$$

we obtain the first statement of the lemma. To see that the second statement is also true, just note that $\left\{\theta_{\ell}^{-}\right\}$can profitably deviate by offering $\left(1, \rho^{-}\right)$ whenever $(t, r)$ does not belong to the closure of $\bar{P}_{\left\{\theta_{\ell}^{+}, \theta_{h}^{-}\right\}}\left(1, \rho^{-}\right)$.

Lemma 4 Suppose $2 \mu_{h} \eta>1$. Then

(i) if $(t, r) \in \bar{P}_{\left\{\theta_{h}^{+}, \theta_{\ell}^{+}, \theta_{h}^{-}\right\}}\left(1, \rho^{-}\right)$and $\wp(t, r)=1$, then $\wp \in \delta\left(\pi^{8}\right)$; and

(ii) $\left(\pi^{8}, \wp\right)$ is not an EPS, for all $\wp \in \delta\left(\pi^{8}\right)$. 
Proof: (i) Our assumptions on the distribution of types prevent a tie between the two parties. Any platform profile of the form $\{(t, r), \varnothing\}$, with $(t, r) \in \bar{P}_{\left\{\theta_{h}^{+}, \theta_{\ell}^{+}, \theta_{h}^{-}\right\}}\left(1, \rho^{-}\right)$, is a $\pi^{8}$-equilibrium since $\left\{\theta_{\ell}^{-}\right\}$has no profitable deviation. This proves (i).

Moreover, if $(t, r)$ does not belong to the closure of $\bar{P}_{\left\{\theta_{h}^{+}, \theta_{\ell}^{+}, \theta_{h}^{-}\right\}}\left(1, \rho^{-}\right)$, then $\left\{\theta_{\ell}^{-}\right\}$can profitably deviate by offering $\left(1, \rho^{-}\right)$(doing so, it wins for sure). As a consequence, the set of electoral outcomes $(t, r)$ arising in EPS involving $\pi^{8}$ is a subset of the closure of $\bar{P}_{\left\{\theta_{h}^{+}, \theta_{\ell}^{+}, \theta_{h}^{-}\right\}}\left(1, \rho^{-}\right)$.

(ii) Suppose $\left(\pi^{8}, \wp\right)$ is an EPS. Then there exists $(t, r)$ such that $\wp(t, r)=$ 1. By definition of an EPS, no coalitional deviation is possible at $\left(\pi^{8}, \wp\right)$. In particular, $\left\{\theta_{h}^{-}, \theta_{\ell}^{+}\right\}$cannot profitably deviate to some $\operatorname{EPS}\left(\pi^{5}, \wp^{\prime}\right)$. As $\bar{P}_{\left\{\theta_{\ell}^{+}, \theta_{h}^{-}\right\}}\left(1, \rho^{-}\right) \subset \bar{P}_{\left\{\theta_{h}^{+}, \theta_{\ell}^{+}, \theta_{h}^{-}\right\}}\left(1, \rho^{-}\right)$, this implies by Lemma 3 that $r=\bar{r}$ and $t \in\left[\bar{t}_{4}, \bar{t}_{5}\right]$.

But, using Lemma 3 again, politician $\theta_{h}^{+}$can induce $\pi^{5}$ and thus enforce $(t-\varepsilon, \bar{r})$ for some $\varepsilon$ arbitrarily small. Obviously, such a deviation is feasible only if $t>\bar{t}_{4}$. As a consequence, $\left(\pi^{8}, \wp\right)$ is an EPS only if $(t, r)=\left(\bar{t}_{4}, \bar{r}\right)$ (if $\left(\bar{t}_{4}, \bar{r}\right) \notin \delta\left(\pi^{5}\right)$, then a deviation by $\theta_{h}^{+}$always occurs $)$.

However this is also impossible. Indeed, coalition $\left\{\theta_{h}^{+}, \theta_{\ell}^{+}\right\}$can induce $\pi^{1}$, and thus enforce a policy $\left(\bar{t}_{4}, \rho^{+}\right)$that makes its members strictly better-off. By Lemma 2, this deviation is feasible since $\bar{t}_{4} \in\left(\bar{t}_{2}, \bar{t}_{1}\right)$. As a result, there is no EPS involving $\pi^{8}$.

We now complete the proof of Proposition 3. First of all, let $P_{1} \subset P$ be defined as

$$
P_{1} \equiv\left\{\left(t^{\prime}, r^{\prime}\right) \in P_{\left\{\theta_{h}^{+}, \theta_{\ell}^{+}, \theta_{\ell}^{-}\right\}}: \forall t \in\left(\bar{t}_{2}, \bar{t}_{1}\right),\left(t, \rho^{+}\right) \notin \bar{P}_{\left\{\theta_{h}^{+}, \theta_{\ell}^{+}\right\}}\left(t^{\prime}, r^{\prime}\right)\right\}
$$

and define the threshold function $\bar{r}:(1 / 2,1) \rightarrow\left(\rho^{-}, \rho^{+}\right)$as

$$
\begin{aligned}
\bar{r}\left(\mu_{\ell}\right) & \equiv \min \left\{r:(t, r) \in P_{1}\right\} \\
& =\rho^{+}-\left(\frac{1-\mu_{\ell}}{\mu_{\ell}}\right)^{1 / 2}\left(\rho^{+}-\rho^{-}\right)>\rho^{-} .
\end{aligned}
$$

The idea is now to check that, for every $j=1, \ldots, 14$, the following statement is true:

$\left(\mathbf{P}_{j}\right)$ Suppose $\mu_{h} \eta>1$. If $\left(\pi^{j}, \wp\right)$ is an EPS with effective parties, then any policy $(t, r) \in P$ such that $\wp(t, r)>0$ satisfies $r \geq \bar{r}\left(\mu_{\ell}\right)$. 
$\left(\mathbf{P}_{j}\right)$ is evidently true for $j \in\{2,3,4,6,10,12\}$ since we know from Lemma 1 that parties cannot be effective in those structures. Let us now turn to the other party structures.

- $j=1$

As any $(t, r) \in P_{\left\{\theta_{h}^{+}, \theta_{\ell}^{+}\right\}}$satisfies $r=\rho^{+}$, statement (i) in Lemma 2 shows that $\left(\mathbf{P}_{1}\right)$ is true.

- $j=5$

Given that $\bar{r}>\bar{r}\left(\mu_{\ell}\right),\left(\mathbf{P}_{5}\right)$ is directly proved by Lemma 3 .

- $j=7$

Since a tie between the two parties is impossible $\left(\mu_{\ell}+\mu_{h}^{+}>\mu_{h}^{-}\right)$, a $\pi^{7}$ equilibrium involves one of them running alone. To see that $\left\{\varnothing,\left(0, \rho^{-}\right)\right\}$is not a $\pi^{7}$-equilibrium when $\mu_{h} \eta>1$, consider for instance a deviation by party $\left\{\theta_{h}^{+}, \theta_{\ell}^{+}, \theta_{\ell}^{-}\right\}$from $\varnothing$ to $\left(\bar{t}_{6}, \mu_{\ell} \rho^{-}+\mu_{h} \rho^{+}\right)$where

$$
\bar{t}_{6} \equiv \frac{\mu_{h}\left(1+2 \mu_{\ell}\right)}{2 \eta \mu_{\ell}} .
$$

It is easy to check that $\bar{t}_{6} \in \bar{P}_{\left\{\theta_{h}^{+}, \theta_{\ell}^{+}, \theta_{\ell}^{-}\right\}}\left(0, \rho^{-}\right)$and then that $\left\{\varnothing,\left(0, \rho^{-}\right)\right\}$is not a $\pi^{7}$-equilibrium.

Consider now platform $\{(t, r), \varnothing\}$, with $(t, r) \in P_{\left\{\theta_{h}^{+}, \theta_{\ell}^{+}, \theta_{\ell}^{-}\right\}}$. Under what conditions is $\left(\pi^{7}, \wp\right)$, with $\wp(t, r)=1$, an EPS? Party structures $\pi^{1}, \pi^{2}$, and $\pi^{4}$ can be induced from $\pi^{7}$. Note first that $\theta_{\ell}^{+}$can induce $\pi^{2}$, and we know from Lemma 1 that $\left(\pi^{2}, \wp\right)$ is an EPS if and only if $\wp\left(1, \rho^{-}\right)=1$. Therefore $(t, r)$ must be in $P_{\left\{\theta_{h}^{+}, \theta_{\ell}^{+}, \theta_{\ell}^{-}\right\}} \cap P_{\theta_{\ell}^{+}}\left(1, \rho^{-}\right) \supset P_{1}$. Moreover, $\left\{\theta_{h}^{+}, \theta_{\ell}^{+}\right\}$can induce $\pi^{1}$ and then, by Lemma 2 , any policy $\left(t, \rho^{+}\right)$such that $t \in\left(\bar{t}_{2}, \bar{t}_{1}\right)$. Consequently, a necessary condition for $\left(\pi^{7}, \wp\right)$ to be an EPS is that $(t, r) \in$ $P_{1}$. This proves $\left(\mathbf{P}_{7}\right)$.

- $j=8$

Part (ii) of Lemma 4 proves $\left(\mathbf{P}_{8}\right)$.

- $j=9$

As $\mu^{-}>1 / 2$, a tie between the two parties is impossible. And since $\left(1, \rho^{-}\right)$is the most-preferred policy of politician $\theta_{\ell}^{+}$in $P_{\left\{\theta_{\ell}^{-}, \theta_{h}^{-}\right\}},\left(\pi^{9}, \wp\right)$ is an EPS only if $\wp\left(1, \rho^{-}\right)=1$. Otherwise, $\theta_{\ell}^{+}$would induce $\pi^{6}$ and then, by Lemma $1,\left(1, \rho^{-}\right)$. But parties are not effective in such an EPS. This establishes $\left(\mathbf{P}_{9}\right)$.

- $j=11$

Consider first an EPS $\left(\pi^{11}, \wp\right)$ in which a single party is running. This implies that $\wp(t, r)=1$ for some $(t, r) \in P_{\left\{\theta_{h}^{+}, \theta_{\ell}^{-}\right\}} \cup P_{\left\{\theta_{h}^{-}, \theta_{\ell}^{+}\right\}}$. As $\theta_{\ell}^{+}$and $\theta_{h}^{-}$can both induce $\pi^{2}$ (and then $\left(1, \rho^{-}\right)$), a necessary condition for $\left(\pi^{11}, \wp\right)$, 
$\wp \neq \wp^{0}$, to be an EPS is consequently

$$
\begin{gathered}
(t, r) \in P_{2} \equiv\left[P_{\left\{\theta_{\ell}^{+}\right\}}\left(1, \rho^{-}\right) \cup I_{\left\{\theta_{\ell}^{+}\right\}}\left(1, \rho^{-}\right)\right] \cap\left[P_{\left\{\theta_{h}^{-}\right\}}\left(1, \rho^{-}\right) \cup I_{\left\{\theta_{h}^{-}\right\}}\left(1, \rho^{-}\right)\right] . \\
\quad \text { If }(t, r) \in P_{2} \cap\left(P_{\left\{\theta_{h}^{+}, \theta_{\ell}^{-}\right\}} \cup P_{\left\{\theta_{h}^{-}, \theta_{\ell}^{+}\right\}}\right) \text {, then either } r=\bar{r}>\bar{r}\left(\mu_{\ell}\right) \text { or }
\end{gathered}
$$
$r=\mu_{h} \rho^{+}+\mu_{\ell} \rho^{-}$. Moreover, for any $(t, r)$ such that $r=\mu_{h} \rho^{+}+\mu_{\ell} \rho^{-}$, there exists $\left(t^{\prime}, r^{\prime}\right) \in \bar{P}_{\left\{\theta_{\ell}^{+}, \theta_{h}^{-}\right\}}\left(1, \rho^{-}\right)$such that politician $\theta_{h}^{+}$strictly prefers $\left(t^{\prime}, r^{\prime}\right)$ to $(t, r)$. As she can enforce $\left(t^{\prime}, r^{\prime}\right)$ by inducing $\pi^{5},\left(\pi^{11}, \wp\right)$ is an EPS only if $r>\bar{r}\left(\mu_{\ell}\right)$.

Consider now an EPS in which both parties are running (a tie). If they offer the same platform, then they are both indifferent between running and not running. According to our initial assumption, they should consequently choose not to run. If they offer different policies, then it is easy to check that the $\pi^{11}$-equilibrium under consideration is not partisan. This ends to prove $\left(\mathbf{P}_{11}\right)$.

- $j=13$

Given the distribution of types, any $\pi^{13}$-equilibrium is of the form $\{(t, r), \varnothing\}$, with $(t, r) \in P_{\left\{\theta_{\ell}^{+}, \theta_{\ell}^{-}, \theta_{h}^{-}\right\}}$. But $P_{\left\{\theta_{\ell}^{+}, \theta_{\ell}^{-}, \theta_{h}^{-}\right\}}$can be partitioned as $P_{\left\{\theta_{\ell}^{+}, \theta_{\ell}^{-}, \theta_{h}^{-}\right\}}=$ $P_{3} \cup P_{4} \cup P_{5}$, where

$$
\begin{gathered}
P_{3} \equiv\left\{(t, r) \in P_{\left\{\theta_{\ell}^{+}, \theta_{\ell}^{-}, \theta_{h}^{-}\right\}}: u\left(t, r, \theta_{\ell}^{+}\right)<u\left(1, \rho^{-}, \theta_{\ell}^{+}\right)\right\} \\
P_{4} \equiv\left\{(t, r) \in P_{\left\{\theta_{\ell}^{+}, \theta_{\ell}^{-}, \theta_{h}^{-}\right\}}: u\left(t, r, \theta_{h}^{-}\right)<u\left(1, \rho^{-}, \theta_{h}^{-}\right)\right\}
\end{gathered}
$$

and

$$
P_{5} \equiv P_{2} \cap P_{\left\{\theta_{\ell}^{+}, \theta_{\ell}^{-}, \theta_{h}^{-}\right\}} \cdot
$$

Let $\left(\pi^{13}, \wp\right)$ be an EPS such that $\wp(t, r)=1$ for some $(t, r) \in P_{\left\{\theta_{\ell}^{+}, \theta_{\ell}^{-}, \theta_{h}^{-}\right\}}$. As $\left\{\theta_{\ell}^{+}, \theta_{\ell}^{-}\right\}$can enforce $\left(1, \rho^{-}\right)$by inducing $\pi_{4},(t, r) \notin P_{3}$. Similarly, $\left\{\theta_{\ell}^{-}, \theta_{h}^{-}\right\}$ can enforce $\left(1, \rho^{-}\right)$by inducing $\pi_{6}$, so that $(t, r) \notin P_{4}$. As a result, policy $(t, r)$ must be an element of $P_{5}$. As $P_{5} \subseteq P_{2}$, we can use the same argument as for " $j=11$ " to show that $r=\bar{r}$, thus proving $\left(\mathbf{P}_{13}\right)$.

- $j=14$

Many party structures can be induced from $\pi^{14}$ but here, we just need to focus on three of them: $\pi^{8}, \pi^{12}$, and $\pi^{13}$.

Let us start with $\pi^{13}$. Under what conditions is $\left(\pi^{13}, \wp\right)$ with $\wp(t, r)=1$ an EPS? We have just seen that $(t, r)$ must belong to $P_{5}$, with $r=\bar{r}$. In step " $j=13$ ", we envisioned all possible deviations except that of $\theta_{\ell}^{-}$to $\pi^{5}$. Actually, politician $\theta_{\ell}^{-}$has a profitable deviation from such a $(t, \bar{r})$ if and 
only if $t<\bar{t}_{5}$. Indeed, in such a case, she can profitably induce $\pi^{5}$ and then $(t+\varepsilon, \bar{r})$. As a consequence, $\left(\pi^{13}, \wp\right)$ is an EPS if and only if $\wp\left(\bar{t}_{5}, \bar{r}\right)=1$.

Let us now return to $\pi^{14}$. Suppose $\left(\pi^{14}, \wp^{14}\right)$ is an EPS. Then $\theta_{h}^{+}$has no profitable deviation to $\pi^{13}$; that is,

$$
\wp^{14}(t, r)=1 \Rightarrow(t, r) \in P_{\left\{\theta_{h}^{+}\right\}}\left(\bar{t}_{5}, \mu_{\ell} \rho^{+}+\mu_{h} \rho^{-}\right) \cup I_{\left\{\theta_{h}^{+}\right\}}\left(\bar{t}_{5}, \mu_{\ell} \rho^{+}+\mu_{h} \rho^{-}\right) .
$$

Furthermore, coalition $\left\{\theta_{\ell}^{+}, \theta_{\ell}^{-}\right\}$must not have an incentive to induce $\pi^{12}$, and then $\left(1, \rho^{-}\right)$; formally,

$$
\wp^{14}(t, r)=1 \Rightarrow(t, r) \in P_{\left\{\theta_{\ell}^{+}\right\}}\left(1, \rho^{-}\right) \cup I_{\left\{\theta_{\ell}^{+}\right\}}\left(1, \rho^{-}\right) .
$$

(Obviously, $\theta_{\ell}^{-}$always agrees with such a deviation.)

Now, assume that $(t, r)$ satisfies (2) and (3), and that $r<\mu_{\ell} \rho^{+}+\mu_{h} \rho^{-}$. This implies that $(t, r) \in P_{\left\{\theta_{\ell}^{+}, \theta_{h}^{-}\right\}}\left(1, \rho^{-}\right) \backslash \bar{P}_{\left\{\theta_{\ell}^{+}, \theta_{h}^{-}\right\}}\left(1, \rho^{-}\right)$. But this in turn implies that there exists a policy $\left(t^{\prime}, r^{\prime}\right) \in \bar{P}_{\left\{\theta_{\ell}^{+}, \theta_{h}^{-}\right\}}\left(1, \rho^{-}\right)$that is strictly preferred to $(t, r)$ by the members of $\left\{\theta_{\ell}^{+}, \theta_{h}^{-}\right\}$and by $\theta_{h}^{+}$. We now prove that $\left(\pi^{5}, \wp^{\prime}\right)$, with $\wp^{\prime}\left(t^{\prime}, r^{\prime}\right)=1$, sequentially blocks $\left(\pi^{14}, \wp^{14}\right)$; a contradiction implying that $r \geq \mu_{\ell} \rho^{+}+\mu_{h} \rho^{-}>\bar{r}\left(\mu_{\ell}\right)$ and thus completing the proof of the proposition.

As all politicians in $\left\{\theta_{h}^{+}, \theta_{\ell}^{+}, \theta_{h}^{-}\right\}$strictly prefer $\left(t^{\prime}, r^{\prime}\right)$ to $(t, r)$, there exists an $\varepsilon>0$ such that: (i) all politicians in $\left\{\theta_{\ell}^{+}, \theta_{h}^{-}\right\}$also strictly prefer $\left(t^{\prime}, r^{\prime}\right)$ to $\left(t^{\prime}, r^{\prime}+\varepsilon\right)$, and $(i i)\left(t^{\prime}, r^{\prime}+\varepsilon\right) \in \bar{P}_{\left\{\theta_{h}^{+}, \theta_{\ell}^{+}, \theta_{h}^{-}\right\}}\left(1, \rho^{-}\right)$. Moreover, the second part of Lemma 4 tells us that there is no EPS involving structure $\pi^{8}$. The following sequence of deviations is then feasible: first, $\left\{\theta_{h}^{+}, \theta_{\ell}^{+}, \theta_{h}^{-}\right\}$induces $\pi^{8}$ and $\left(t^{\prime}, r^{\prime}+\varepsilon\right)$ (see (i) in Lemma 4$)$, and then $\left\{\theta_{\ell}^{+}, \theta_{h}^{-}\right\}$induces $\pi^{5}$ and $\left(t^{\prime}, r^{\prime}\right)$.

\section{References}

Austen-Smith, D., Wallerstein, M., 2006. Redistribution and Affirmative Action. Journal of Public Economics 90, 1789-1823.

Besley, T., Coate, S., 1997. An Economic Model of Representative Democracy. Quarterly Journal of Economics 108, 85-114.

Esteban, J.M., Ray, D., 1994. On the Measurement of Polarization. Econometrica $62,819-851$.

Fernández, R., Levy, G., 2008. Diversity and Redistribution. Journal of Public Economics 92, 925-943. 
Glaeser, E.L., 2005. The Political Economy of Hatred. Quarterly Journal of Economics 120, 45-86.

Kitschelt, H., 1994. The Transformation of European Social Democracy, New York: Cambridge University Press.

Laver, M., Hunt, W. B., 1992. Policy and Party Competition, New York: Routledge.

Lee, W., Roemer, J., 2005. Racism and Redistribution in the United States: A Solution to the Problem of American Exceptionalism. Journal of Public Economics 87, 2491-2505.

Levy, G., 2004. A Model of Political Parties. Journal of Economic Theory $115,250-277$.

Morelli, M., 2004. Party Formation and Policy Outcomes under Different Electoral Systems. Review of Economic Studies 71, 829-853.

Osborne, M., Slivinski, A., 1996. A Model of Political Competition with Citizen-Candidates. Quarterly Journal of Economics 111, 65-96.

Poole, K. T., Rosenthal, H., 1991. Patterns of Congressional Voting. American Journal of Political Science 35, 228-278.

Ray, R., Vohra, R., 1997. Equilibrium Binding Agreements. Journal Economic Theory $73,30-78$.

Roemer, J., 1998. Why the Poor do not Expropriate the Rich?: An Old Argument in New Garb. Journal of Public Economics 70, 399-424.

Roemer and Van der Straeten, 2004a, Xenophobia and Distribution in France: A Politico-economic Analysis, mimeo.

Roemer and Van der Straeten, 2004b, The Political Economy of Xenophobia and Distribution: The Case of Denmark, mimeo.

Roemer and Van der Straeten, 2005, Politiques sociales et immigration en France: une analyse des opinions et des comportements électoraux, Economie Publique $\backslash$ Public Economics, 16: 83-116. 


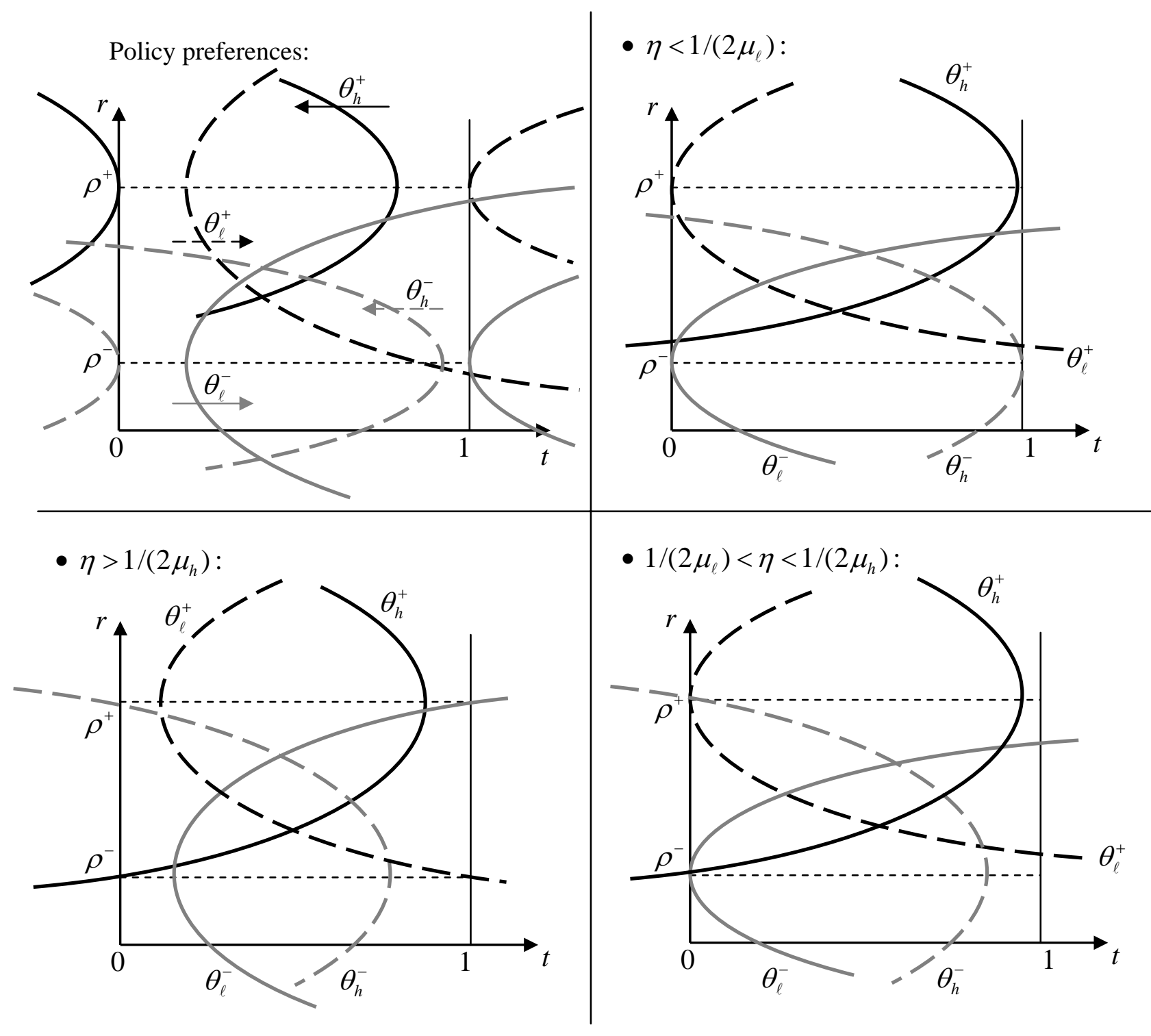

Figure 1: Policy Preferences and the Saliency of the Redistribution Issue 
$\underline{\text { Table 1: Distribution of types }}$

\begin{tabular}{c|cc|c} 
& $\rho^{-}$ & $\rho^{+}$ & $\sum$ \\
\hline$\omega_{\ell}$ & $\mu_{\ell}^{-}$ & $\mu_{\ell}^{+}$ & $\mu_{\ell}$ \\
$\omega_{h}$ & $\mu_{h}^{-}$ & $\mu_{h}^{+}$ & $\mu_{h}$ \\
\hline$\sum$ & $\mu^{-}$ & $\mu^{+}$ & 1
\end{tabular}

